\title{
Schutz vor Asthma durch Omega-3-Fettsäuren in Bauernhofmilch
}

\begin{abstract}
Auf einem Bauernhof aufzuwachsen ist mit einem geringeren Risiko verbunden, allergische Atemwegserkrankungen und Sensibilisierungen zu entwickeln, als eine Kindheit in der Stadt. Ein Teil des Schutzes ist auf den Verzehr der hofeigenen Milch und Butter zurückzuführen. Doch über die Wirkmechanismen wird noch spekuliert. Eine aktuelle Veröffentlichung führt den protektiven Effekt von Bauernhofmilch bezüglich kindlichem Asthma nun unter anderem auf einen höheren Gehalt an $\omega$-3-Fettsäuren und deren antientzündlichem Potenzial zurück.
\end{abstract}

E ine Auswertung der Follow-up-Daten Eder PASTURE-Kohorte („Protection Against Allergy - Study in Rural Environments") hat diese neue Einschätzung ermöglicht. Von ursprünglich $751 \mathrm{Stu}-$ dienteilnehmern aus ländlichen Regionen Deutschlands, Österreichs, Frankreichs und der Schweiz $(\mathrm{n}=351$ vom Bauernhof, $n=400$ Kontrollen), die bei der Nachuntersuchung mit vier Jahren Proben der konsumierten Milch abgeliefert hatten, wurden nach sechs Jahren 84 Kinder ( $\mathrm{n}=35$ mit Diagnose Asthma, $\mathrm{n}=49$ gesunde Kinder als Kontrolle) als Fall-Kontroll-Population ausgewählt. Gesunde Kinder kamen zu gut der Hälfte (26/49), Asthmatiker zu knapp der Hälfte (16/35) vom Bauernhof. Beide Gruppen unterschieden sich deutlich im Konsum unverarbeiteter Bauernhofmilch und dementsprechend auch hinsichtlich des Fettgehaltes der verzehrten Milch. Während der Fettanteil in handelsüblicher Milch in der Regel auf 1,5\% (fettarm) oder 3,5\% (vollfett) standardisiert ist, enthält unverarbeitete Bauernhofmilch deutlich mehr Fett (in der vorliegenden Untersuchung durchschnitt- lich 4,0\%). Der Trend, mehr unerhitzte Bauernhofmilch zu trinken, stieg nach dem zweiten Lebensjahr kontinuierlich. Wesentliche Unterschiede:

—Während 17 der gesunden Kinder vorwiegend unerhitzte Milch vom Hof zu sich nahmen, taten dies nur drei der Asthmatiker.

_Der Fettgehalt konsumierter Milch lag bei 26 der gesunden Kinder über den handelsüblichen 3,5\%, während nur ein Drittel der Kinder mit Asthma fettreiche Milch verzehrten.

_-Die Effekte des Konsums unerhitzter Bauernhofmilch auf die Entstehung eines Asthma nahmen tendenziell mit steigendem Alter zu: Während mit einem Jahr eine Risikominderung um $49 \%$ zu sehen war, erhöhte sich dieser Effekt im Alter von fünf Jahren auf $71 \%$. Dabei war die protektive Wirkung auf ein leichtes Asthma ausgeprägter als auf ein schweres Asthma.

Insbesondere der Gehalt der Milch an $\omega$-3-Fettsäuren unterschied sich zwischen Kindern mit und ohne Asthma deutlich: Kinder mit Asthma konsu- mierten Milch, deren $\omega-3-$ Gehalt um $35 \%$ niedriger war. Selbst vollfette Milch aus dem Handel enthielt weniger $\omega$-3-Fettsäuren als unerhitzte Bauernhofmilch. Bei relativ stabilen $\omega-6$ Anteilen in allen Milchproben ergab sich für fettarme Milch aus dem Handel ein $\omega$-6-/ $\omega$-3-Verhältnis von 3,38: 1 verglichen mit 1,75:1 für vollfette Milch und 1,59:1 für unerhitzte Bauernhofmilch.

Ein ungünstiges $\omega-6 / \omega-3$-Verhältnis fördert Entzündungen, was als ein Grund für die Zunahme von allergischen Erkrankungen angenommen wird. In der vorliegenden Untersuchung war es positiv mit Serumwerten für das hochsensitive C-reaktive Protein (hsCRP) als Marker für Entzündung assoziiert.

Fazit: Eine protektive Wirkung von langkettigen $\omega$-3-Fettsäuren auf die Entstehung allergischer Erkrankungen wird seit längerem beobachtet. Allerdings beziehen sich die meisten Untersuchungen auf den Verzehr von Fisch oder die Supplementation mit Fischölkapseln. Der präventive Effekt wird den langkettigen $\omega$-3-Fettsäuren direkt, aber auch indirekt über eine Verbesserung des Verhältnis von $\omega-6-\mathrm{zu} \omega-3$ Fettsäuren zugeschrieben. Die vorliegende Untersuchung hat nun auch in unerhitzter Bauernhofmilch $\omega$-3-Fettsäuren als mögliche Schutzfaktoren gegen die Entstehung eines Asthmas identifiziert.

Dr. Imke Reese

Brick T et al. $\omega-3$ fatty acids contribute to the asthma-protective effect of unprocessed cow's milk. J Allergy Clin Immunol 2016; doi: 10.1016/j.jaci.2015.10.042

\section{Was dem Schwein seine Katze, ist dem Pferd sein Hund}

Schon länger ist bekannt, dass Katzenallergiker auch auf Schweinefleisch allergisch reagieren können. Luxemburger Immunologen haben nun erstmals für Hund und Pferd eine ähnliche Kreuzreaktion beschrieben.

m Mittelpunkt der Fallbeschreibung, die Martine Morisset (Luxemburg) zusammen mit Kollegen vorgelegt hat, steht eine 38-jährige Frau. Sie wird mit exazerbiertem Asthma in der Klinik von Luxemburg vorstellig. Erstmals war die Erkrankung aufgetreten, als sie sich 2008 einen Hund zugelegt hatte. Als sie den Beagle streichelte, trat eine Urtikaria auf. Über oropharyngealen Juckreiz, Schnupfen mit Niesattacken und verstopfter Nase wanderte das Krankheitsgeschehen über Husten und Giemen nach und nach in die tieferen Atemwege.

Kontakt zu Katzen und Hunden hat die Frau schon seit früher Kindheit. Anamnestisch gibt sie an, seit 1992 auf 